\title{
Hein-Lehmann 型遠心脱水機による眖水についで
}

山口賢治**

理化学研究所

脱水過程に関しては，Brownell-Katz ${ }^{3)}$, Nenniger-

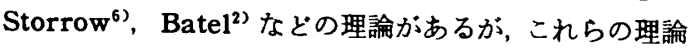
を実際の脱水装置に適用し，検討した研究は非常に少な い。ここでは，膜流れの機構を仮定した脱水過程の考え 方を用いて, 馬場氏の Hein-Lehmann 型（円錐ハスケ ット完全自動排出型連続）遠心脱水機の実験結果1)を整 理し直してみたので報告する。

上にあげた脱水過程の各関係式は，脱水㭙間 $t$ が大き い範囲では

$$
S_{a_{0}}-S_{a 000}=C^{\prime}\left(\frac{Z_{\rho g} K t}{\mu_{\varepsilon} L}\right)^{-m}
$$

の形にまとめて表わすことができる゙す。 $S_{a v}$ は全空吵と 含有液との体積比で表わした平均含液率（空隙合液率， 鴭和度）を示す。 $C^{\prime}$ は定数である。

連続遠心脱水機において，そのホルド・アッブを $W$ [乾燥固体 $\mathrm{kg}$ ] とすれば，固体の装置内平均带留時間 $\tau$ お上び平均層厚 $L_{a v}$ はそれそれ次のよ5に表わされる。

$$
\tau=\frac{W}{Q}, \quad L_{a v}=\frac{W}{(1-\varepsilon) \rho_{p} A}
$$

ただし， $A$ は脱水に有効な部分の面積， $Q$ は供給速度 で，単位時間内に供給される乾燥固体の量で表わす。

（1）式 $t$ の代わりに $\tau, L$ の代わりに $L_{a v}$ を圈き换 之，含液率 $S_{a v}$ を一般に用いられる重量百分率 $w_{a v}$ K 換算すると同式は次のよ5になる。

$$
w_{a v}-w_{a v 00}=C\left(\frac{Z_{0}}{Q}\right)^{-m}[\%]
$$

Cは式の展開の上では，近似的に，

$$
C=\phi \frac{\varepsilon \rho}{(1-\varepsilon) \rho_{p}} C^{\prime}\left[\frac{(1-\varepsilon) \rho_{p} A \rho g K}{\mu_{\varepsilon}}\right]^{-m} \times 100
$$

と表わされるか，実際上は，全体としてのCを等置の 式, 操作条件, 代表値のとり方, 処理する固体および夜 体の性質などに関する係数とみなす方が適当であろう。 $Z_{0}$ はバスケットの代表的な位直の遠心奻果を示す。 $\phi$

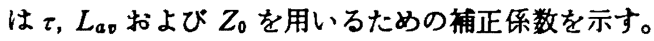

Fig. 1 は馬場氏の実測値を整理し直した結果で，各実 測値が（3）式の形にまとめられることを示している。 図中の実線は, Brownell らの結論から求めた $m=0.67$ を用いて得た次の実験式を示す。

* <On Dewatering by Hein-Lehmann-Type Centrifugal Filter $>$

Received on May 19, 1965

** Kenji Yamaguchi (The Institute of Physical and Chemical Rescarch, Tokyo, Japan)

$$
w_{a v}-w_{a v 00}=1.2\left(\frac{Z_{0}}{Q}\right)^{-0.67} \quad[\%]
$$

実用脱水機では，固体の供給機棈，バスケットの微小 な振動などによって，粒子層内の飽和域は除去されるの が普通である。飽和城が存在しない場合， $S_{a v 00}\left(w_{a v 00}\right)$ はとりむなおさず低湿分域の含液率 $S_{\infty}\left(w_{\infty}\right)$ に等しい。 $S_{\infty}$ はキャピラリ数が $10^{-3}$ 以下では, $Z$ に関係なく一定 である。馬場氏のデータから推算すると，その実験籁囲

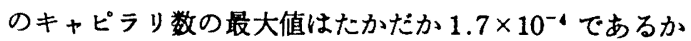
ら、 $w_{\infty}$ したがって $w_{a v 00}$ は一定とみなされる。

同氏の $w_{a v}$ 対 $Z_{0}$ の実測値 $(Q=2$ ton $/ \mathrm{hr})$ から, 上 の結論に従って $w_{a v 00}$ を求めると $1.7[\%]$ である。そこ でさきに求めた関係（5）式にこの值を代入すれば,

$$
w_{a v}=1.7+1.2\left(\frac{Z_{0}}{Q}\right)^{-0.67}
$$

となる。Table 1 は $Q=2$ ton $/ \mathrm{hr}$ のときの実測値と（6）

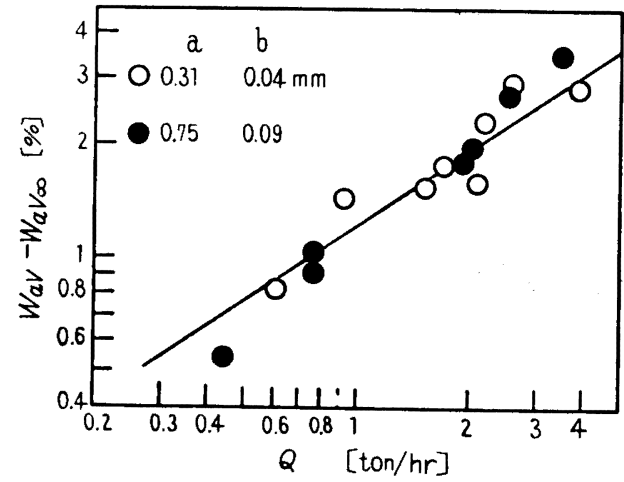

Fig. 1 Correlation between $w_{a v}-w_{a v o}$ and $Q$

Table 1 Values of $w_{a v}^{*}$

\begin{tabular}{rcc}
$Z_{0}[-]$ & \multicolumn{2}{c}{$\begin{array}{c}\text { value of } w_{a v}[\%] \\
\text { observed }\end{array}$} \\
\hdashline 642 & calculated & 4.9 \\
1,220 & 2.6 & 2.8 \\
2.060 & 2.9 & 2.2
\end{tabular}

* $Q=2$ ton $/ \mathrm{hr}, a=0.425, b=0.09 \mathrm{~mm}$ 
式から求めた值の比較で，㹈品含液率のばらつきを考虑

すればよく一致しているといえる。

以上（3）式は Hein-Lehmann 型遠心脱水機の脱水 特性を表わすのに適当であることを示したが，指数 $m$
は Nenniger らの示した値 0.5 よりす大きく, Brownell らの結果から求められる0.67.上りす若干大きい。実䟢 には $m$ および定数 $C$ は実験的に求めるへきであろう。

\begin{tabular}{|c|c|c|c|c|}
\hline \multicolumn{5}{|c|}{ Nomenclature } \\
\hline$A:$ & area of screen availavle for dewate & ring & $Z$ : centrifugal effect & {$[-]$} \\
\hline & & {$\left[\mathrm{m}^{2}\right]$} & $Z_{0}:$ value of $Z$ at the lip of basket & {$[-]$} \\
\hline$a:$ & ratio of solid to liquid in feed & {$[-]$} & $\varepsilon:$ porosity & {$[-]$} \\
\hline$b:$ & screen aperture & {$[\mathrm{m}]$} & $\mu:$ viscosity & {$[\mathrm{kg} / \mathrm{m} \cdot \mathrm{hr}]$} \\
\hline$C, C^{\prime}:$ & constant, see Eq. (4) and (1) & & $\rho:$ density of liquid & {$\left[\mathrm{kg} / \mathrm{m}^{3}\right]$} \\
\hline$g:$ & acceleration due to gravity & {$\left[\mathrm{m} / \mathrm{hr} \mathbf{r}^{2}\right]$} & $\rho_{p}:$ density of solid & {$\left[\mathrm{kg} / \mathrm{m}^{3}\right]$} \\
\hline$K:$ & permeability of bed & {$\left[\mathrm{m}^{2}\right]$} & $\tau:$ average residence time of solid & in basket \\
\hline$L:$ & height or thickness of bed & {$[\mathrm{m}]$} & & {$[\mathrm{hr}]$} \\
\hline$m:$ & exponent & {$[-]$} & $\phi:$ coefficient, see Eq. (4) & \\
\hline$Q:$ & solid feed rate & $\lfloor\mathbf{k g} / \mathbf{h r}\rfloor$ & & \\
\hline$S:$ & saturation & {$[-]$} & & \\
\hline$t:$ & dewatering time & {$[\mathrm{hr}]$} & Subscripts & \\
\hline$W:$ & hold-up of solid in basket & {$[\mathbf{k g}]$} & $a v:$ average & \\
\hline$w:$ & moisture content, weight percent & {$[-]$} & $\infty$ : equilibrium state & \\
\hline
\end{tabular}

Literature cited

1) Baba, M.: Kagaku Kögaku (Chem. Eng., Japan), 23, 843 (1959)

2) Batel, W. : Chem.-Ing.-Tech., 33, 541 (1961)

3) Brownell, L. E. \& D. L. Katz: ¿Chem. Eng. Progr., 43, 601, 703 (1947)

Brown, G. G. : Unit Operations, 220 (1951)

4) Dombrowski, H. S. \& L. E. Brownel1: Ind. Eng. Chem., 46. 1207 (1954)

5) Inoue, I. \& K. Yamaguchi : Kagaku Kōgaku (Chem. Eng, Japan), 29, 261 (1965)

6) Nenniger, E. Jr. \& J. A. Storrow : A. I. Ch. E. Journall, 4. 305 (1958)

\section{会虽の悥}

\section{小久保氏ら「Kristal-Oslo 型結晶装而による喽安の晶析」 に対する Bamforth 氏の反培}

本誌 1964 年 2 月号に発表された，小久保，筑木雨氏の諭文 ${ }^{1}$ 「Kristal-Oslo 型結晶装国による硫安の晶析について」に网し， イギリス Power Gas Corporation の Crystallizer Dept. の Chief engineer, A. W. Bamforth 氏が22 反論を発表し ているので釈介する。

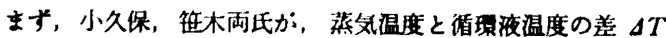
を記録し，良好な製品を作り得る $\Delta T$ の取大値を示しているの に対し，Bamforth 氏は，この $\Delta T$ は過鴒和との相関闺係を正 しく示すあのではなく，過就度こそ正しい指数であるとしてい る。つまり，連䌇式クリスタル型クリスタライザーの生産量 は，刢り出される過䭒和の度合に正比例し，またある定まった

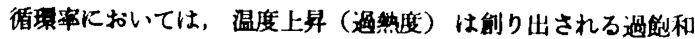
に正比例するから，生産胃は過熱度に正比例するとしている。

また，小久保氏らか，クリスタル型クリスタライザーの操作

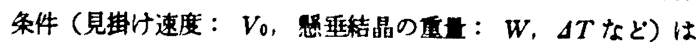

㹨い籍围にあり、これらの制御には敩密さを要求されるとして いろのに対し，Bamforth 氏は，小久保氏らの実非か： $V_{0}$ ， と して，14.9\%を平㚬として变化梗 $20 \%$ の条件において，一贯し て得られたこと，また液循棵率は12〜28\%の变轩が明らかにさ れていることを指揞し，両氏の実検の扬合は实験装专によって 分級照垂を目指したため当然この循環率に制限されたのであっ て，工莱装情の軥合には，さらに大きな幅で变化が可能であり， 結晶が循噮することをある程度許容しても，製品の粒度，品資 がさして爸化することはない，としている。

以上の他，Bamforth 氏は，本格スケール装哣と試験機との 比慗，昆噼の变化などの点に召及している。

1) 小久体, 证木；化学工学, 28, Feb (1964)

2) Bamforth, A. W. : Chem. Proecss Eng., P. 81, Feb (1965) [三娄化工 (株) 黑沢] 


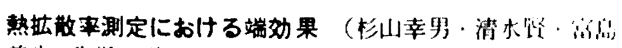
義生，化学工学，29，974９80（1965））周䏣法に上り热厸

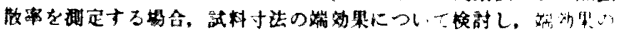

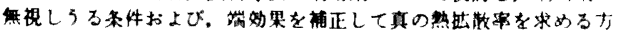

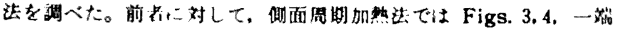

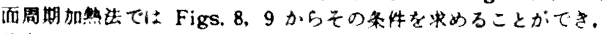

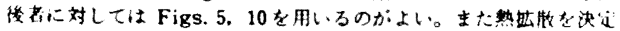

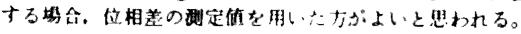

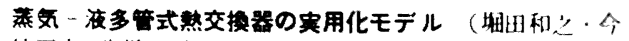

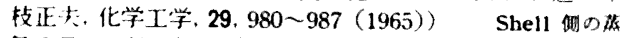

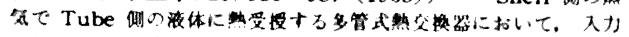

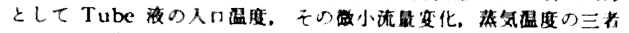

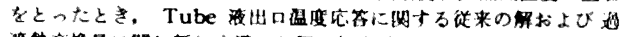

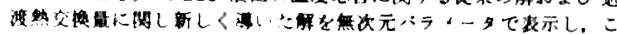

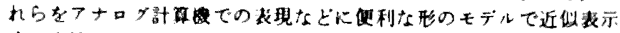

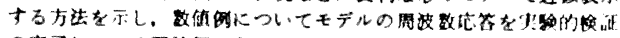

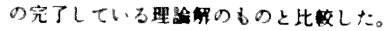

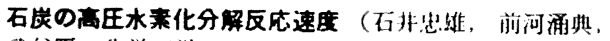
武谷孯, 化学工学、29，988 995 (1965)) 北每道産现

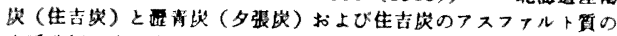

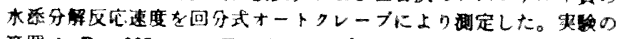
粗: $P_{r}=225 \mathrm{~atm}, T_{r}=300 \sim 450^{\circ} \mathrm{C}, t_{r}=0 \sim 200 \mathrm{~min}$ でる。

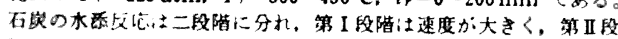

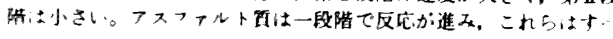

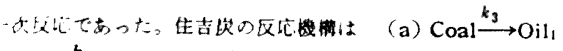

(b) Coal $\stackrel{k_{1}}{\longrightarrow}$ Asphaltene $\stackrel{k_{2}}{\longrightarrow}$ Oil? の並行反论て。第 II 段階で

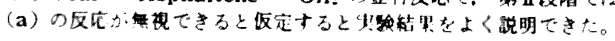

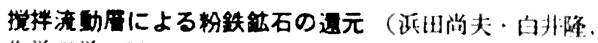

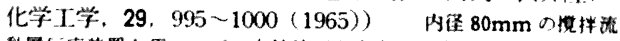

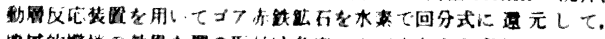

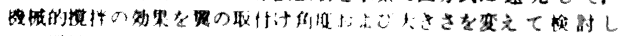

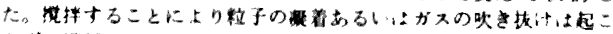

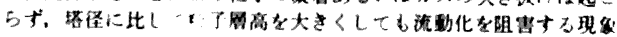

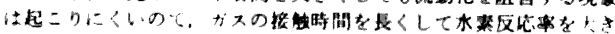

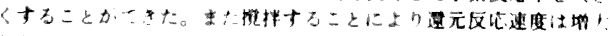
Li。

回分式リボン湿合機の混合性能に及ほすリボン形状むよ

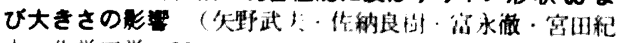

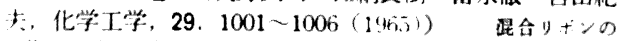

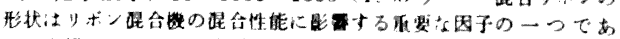

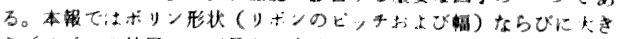

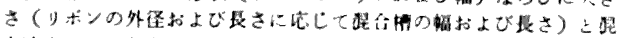

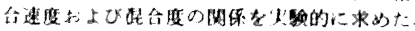

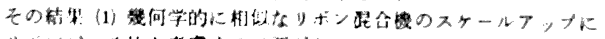

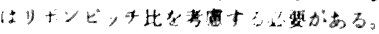

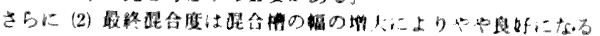

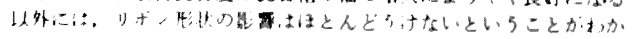
oti.

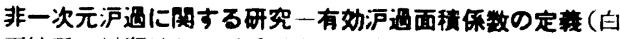

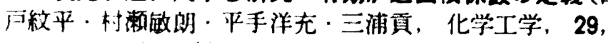

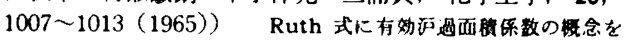

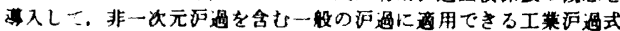

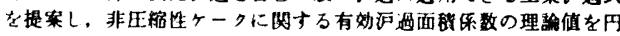

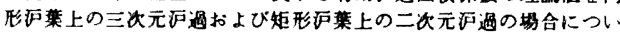
て道いた。これらの理铪颠と，正樎性指数 0.12〜0.70のスラリに

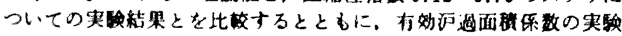

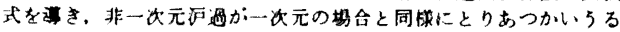
ことを宁した。

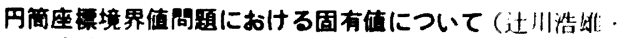

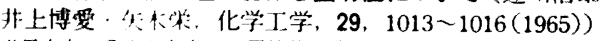

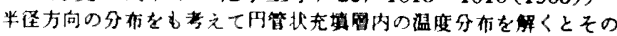

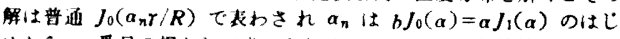

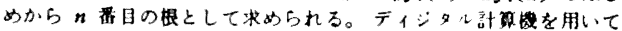

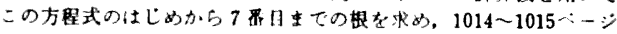
の Table 1 に示した。

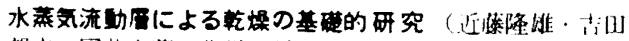
据专・国非大成，化学工学，29，1016１017 (1965))

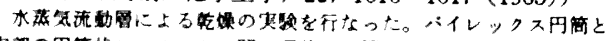

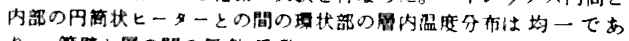

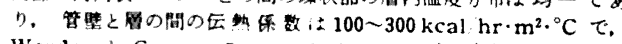

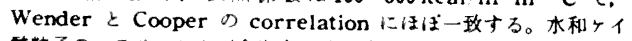

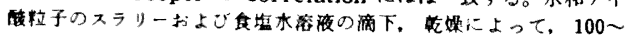

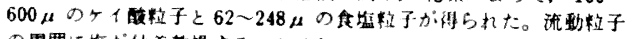

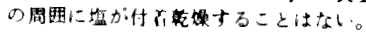

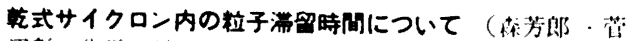
沼彰, 化学工学, 29.1018 (1965)) 板式廿イクロン内

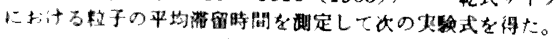
$\left.\tau_{p} V D\right)=k_{p} C^{-3 / 4}\left(V^{2} / g D\right)^{4 / 3}$

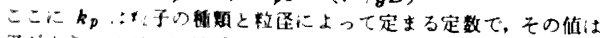

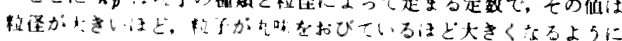
思いれる。
}

Hein-Lehmann 型薏心脱水譏による脱水について（山 门留店，化学工学，29，1019 1020 (1965) Hein

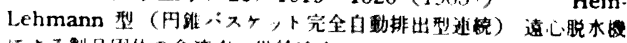

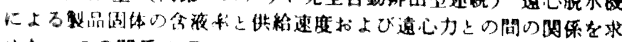
めた。二の成倸: Brownell-Katz および Nenniger-Storrow

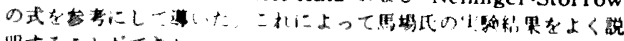
明することができた。 